infections extends all through childhood, while rickets is common only within certain well-defined age limits. In childhood, however, we recognise certain well-marked stages of development. In the first few months of life it is the digestive function which is so hypertrophied that it attracts all attention to itself, so that infections of all sorts, as, for instance, the common infectious cold which sometimes passes through a whole household, are apt to take on themselves the appearance of primary alimentary disorders. Later locomotion and the increased activity of the boneforming elements which takes place under the stimulus of walking become in turn prominent. How great is the change in the skeleton which the assumption of the upright posture and the stimulus of walking produce. The legs, which up to that time have been active, if somewhat inefficient, prehensile organs, become modified into organs of support. The pelvis and the chest undergo a rapid expansion, the abdomen relatively recedes, and the curves of the spine are altered. If, however, as a result of repeated or persistent infection the motor activities of brain, nerve, and muscle are inhibited, this moulding of the skeleton is delayed and in bad cases prevented. This period of high functional activity and the period of the increased liability to rickets correspond. Within this age limit a high proportion of infected children develops some signs of rickets. That many escape is to be expected. Similarly, the syphilitic toxin, which in general shows the same affinity for the epiphyses, is often content to leave the bony system unaffected.

Caicium metabolism in rickets. -That pyrexial disturbances in infancy and childhood are accompanied by profound alterations in the retention and excretion of salts is shown by the great and sudden fluctuations in the body weight. In certain children convulsions and tetany, accompanied often by odema of the extremities, are almost invariable accompaniments of a pyrexial attack, and it is significant that a very large proportion of children with tetany are also rickety.

Kxperiments upon calcium metabolism in rickets have given very contradictory results. In most cases the research period has been as short as three or four days, and it is clear that in a disorder of such long duration as rickets little information of value can be obtained from the mere presence or absence of a negative calcium balance in that short period. I know of no work which has been undertaken to estimate the calcium balance of rickety children suffering from pyrexia. On the general question, however, of the calcium metabolism during pyrexia, it would appear that excretion may be increased.

Rival viens of the origin of riokets. - There is at the present time some tendency for a sharp difference of opinion to arise as to the cause of rickets. There are those who hold that the disorder is a " diet deficiency" disease ; there are others who will have none of this view, and regard it as a disease of "domestication or urbanisation." Dr. Leonard Findlay has shown the ill-effect of confinement and lack of exercise in puppies. Dr. Eric Pritchard has emphasised the evils of over-feeding. The cause has even been found in hypothrroidism, and the thyroid as well as other ductless glands have been implicated. If rickets be no more than the temporary inhibition of osteoblastic activity during infective processes of all sorts, upsetting the balance which maintains in health between osteoblast and osteoclast, if the softening of the bones is comparable to the accompanying amyotonia, to the devitalisation of the skin and mucous membranes, to the irritation and exhaustion of nervons tissue, and to the diminished activity of ductless glands, then we can accept all of these rival claims as playing a part in lowering the immunity of the child against infection. The child who is fed npon an excess of carbohydrate food, the child who is kept away from fresh air and sun and who has no opportunity for free movement, and who is in close contact with infected persons is prone to frequent if transient infection. In our study of such a disorder as rickets we must not omit to keep the child himself in the foreground. We must attempt to isolate and weigh the effects even of such imponder. abilia as the common and frequently repeated household cold. An analysis of the symptoms ordinarily attributed to rickets such as is presented in the report by Dr. Findlay is bistorically interesting, and a survey of the social and economic factors such as Miss Ferguson contributes is of the very highest practical atility. It is, however, the reaction of the child to the evils which she discloses which $d \in$ mands closer study. If from such a study we are able to shift our ground a little and regard as the factor of chief etiological significance not the refusal of the osteoid tissue to undergo ossification, but the lowering of immunity and the repetition of catarrhal infections of the respiratory and alimentary tracts, then we shall have less reason to dispute as to the importance of rival "causes of rickets." For all will then be recognised as important and we shall have an explanation in keeping with the coincident changes in other tissues of the body, changes which are clearly the result and not the cause of the state of infection. I am, Sir, yours faithfully,

Devonshire-place, W., Nov. 2nd, 1918. H. Charkes CAMmRoN.

\section{ACCESSORY FOOD FACTORS IN INFANT FEEDING.}

To the Editor of THE LANCET.

SrR,-In his extremely interesting contribution to THE LANCET of Oct. 12th on the subject of infant feeding Dr. I. C. Drummond refers to the use of Marylebone cream in combination with separated dried milk as a food for babies, and states that he would expect to find that children fed on such a mixture would show diminished resistance to disease in spite of apparent normal development. As I have had some five or six years' experience of feeding infants at my centre in accordance with this method, my experience may not be without interest.

I have not had much experience with the use of ordinary Marylebone cream (made with linseed oil) in combination with dried separated milk, because after a short trial I gave it up for the very reasons predicted by Dr. Drummond, but I have had some experience of "modified" Marylebone cream, used with separated milk, and the results have been excellent. "Modified" Marylebone cream is made from soya-bean oil ; cotton-seed oil and suet in such proportions that the resulting combination contains approximately the same percentage of the neutral fats, olein palmatin, and stearin as butter fat contains. I thoroughly endorse Dr. Drummond's view that the real criterion of good nutrition is resistance to disease. Judged on this ground, I find that infants fed on dried separated milk modified to the standard of breast-milk with sugar and Marylebone cream of the above variety compare not unfavourably with artificially fed infants reared on other dietaries, in spite of the fact they are drawn from the poorest class of infants attending at the consultations. I may add, however, that these infants, in common with all other hand-fed infants attending at $m y$ centre, are invariably provided with three other accessory food elements-namely, with the "watersoluble $C$ " element by giving fruit-juice or turnip-juice, with the "water-soluble $B$ " element by giving daily 1 oz. of meat and vegetable broth, and with lecithin bodies by giving daily either a small quantity of the yelk of egg or a few grains of glycerophosphate of calcium, which seems to answer the same purpose in lending stability to the nerve cell.

I have been using dried milks of all kinds during the last ten years for infant feeding, at first without the addition of these accessory factors and for the last five years in combination with them; the results are, in my opinion, astonish. ingly better when the accessory factors are added.

Harley-street, W., Nov. Ist, 1918. ERIC PRTYChat a

\section{NASAL DISINFECTION.}

To the Editor of THE L ANGET.

SrR,-There is a large group of infectious diseases in which the infective organisms live and apparently multiply in the naso-pharynx and the accessory sinuses. Typical instances of these diseases are scarlet fever, diphtheria, and cerebro-spinal fever. The organisms are found sometimes in patients who have suffered from the disease, sometimes in healthy carriers. They often persist for a long time, are difficult to destroy, and are a frequent cause of spread of infection, especially when a nasal discharge occurs. My own experience has been almost entirely in connexion with scarlet fever and diphtheria as treated in hospital, and in these diseases the difficulty of getting rid of infection is notorious. Antiseptics, applied by spraying, syringing, inhalation, or otherwise, have all failed, and it almost 